\title{
АТОМНІ ЛАНЦЮЖКИ ХЛОРУ НА ПОВЕРХНІ Ag(111)
}

\author{
Н.В. ПЕТРОВА, І.М. ЯКОВКІН, О.М. БРАУН
}

УдК 538.91, 538.971, 538.915

(Просn. Науки, 46, Київ 03028; e-mail: yakov@iop. kiev.ua)

\begin{abstract}
Формування ланцюжкових структур хлору на поверхні $\mathrm{Ag}(111)$ досліджено методом Монте-Карло із використанням параметрів латеральної взаємодії, розрахованих методом теорії функціонала електронної густини. Показано, що формування ланцюжків зумовлене непрямою взаємодією між адатомами хлору, що є наслідком фриделівських осциляцій електронів провідності при екрануванні частково заряджених адатомів. Проведене моделювання дозволяє пояснити послідовність формування структур хлору на поверхні $\mathrm{Ag}(111)$, що спостерігаються в експерименті. Зокрема, з'ясовано механізм переходу від ланцюжкової до гексагональної структури $(\sqrt{ } 3 \times \sqrt{ } 3) \mathrm{R} 30^{\circ}$ при збільшенні ступеня покриття до $\theta=0,33$.
\end{abstract}

\section{1. Вступ}

Практична важливість детального вивчення властивостей адсорбованих шарів хлору на поверхні срібла зумовлена, насамперед, властивістю $\mathrm{Cl}$ підвищувати селективність каталітичної реакції окислення етилену, що використовується в хімічній промисловості. Адсорбцію $\mathrm{Cl}$ на $\mathrm{Ag}(111)$ широко досліджено різними методами, зокрема, дифракції повільних електронів (ДПЕ) [1-5], поверхневої спектроскопії тонкої структури поглинання рентгенівського проміння (SEXAFS) [5, 6], термодесорбції [2, 3], ожеелектронної спектроскопї (ОЕС) [1-3], скануючої тунельної мікроскопії (СТМ) [4, 7-9], а також теоретично методами теорії функціоналу електронної густини (DFT) і Монте-Карло [10-16]. Адсорбція хлору на поверхні $\mathrm{Ag}(111)$ відбувається з дисоціацією молеку-
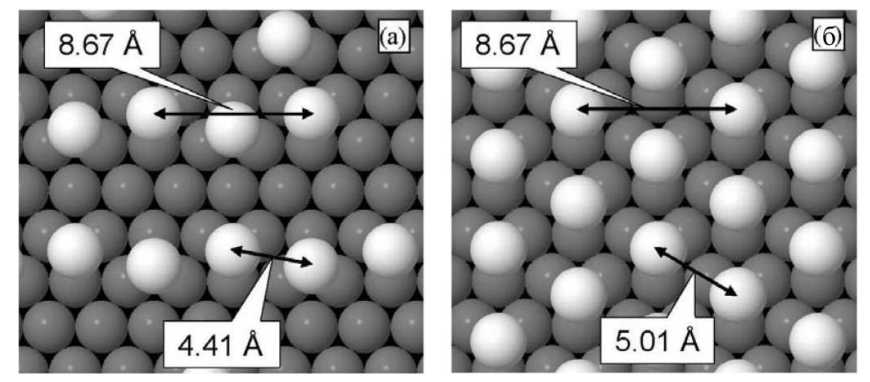

Рис. 1. Ланцюжки адатомів хлору на поверхні $\operatorname{Ag}(111)$ (a) та структура $(\sqrt{ } 3 \times \sqrt{ } 3) \mathrm{R}^{\circ}(\sigma)$ ли $\mathrm{Cl}_{2}$ (екзотермічна реакція з практично нульовим активаційним бар'єром [2]). Початковий коефіцієнт прилипання $\mathrm{Cl}$ на поверхні $\mathrm{Ag}(111)$ становить 0,4 [3] і при кімнатній температурі для покриттів до половини моношару (МШ) хлор не дифундує в підкладку, і атоми хлору залишаються в хемосорбованому стані на поверхні $[14,17]$.

У недавніх дослідженнях структури хлору на поверхні $\mathrm{Ag}(111)$, проведених методом СТМ при температурі поверхні 5 K [9], було знайдено, що адатоми при покриттях у діапазоні від 0,03 до 0,31 формують ланцюжки, довжина і кількість яких зростає при збільшенні ступеня покриття. Так, при малих покриттях атоми хлору створюють фрагменти ланцюжків, причому з однаковими міжатомними відстанями, що дорівнюють 4,4-4,5 $($ рис. 1, a). При покриттях більших 0,25 , одночасно з ланцюжковими структурами, починають формуватися острівці структури $(\sqrt{ } 3 \times \sqrt{ } 3) \mathrm{R}^{\circ} 0^{\circ}$ (рис. $\left.1, \sigma\right)$, що при $\theta=0,33$ займає практично всю поверхню (ця структура була спостережена методами ДПЕ і СТМ $[4,5,8])$.

Важливо відзначити, що міжатомні відстані у структурі $(\sqrt{ } 3 \times \sqrt{ } 3) \mathrm{R} 30^{\circ}$ становлять 5,01 $\AA$, що суттєво перевищує відстань між адатомами хлору в ланцюжках, що створюються при менших покриттях. Ця особливість свідчить про складний характер латеральної взаємодії. Справді, якщо припустити, що притягання між адатомами хлору, зумовлене непрямою взаємодією, приводить до того, що міжатомна відстань 4,4 виявляється вигідною, так що при малих покриттях утворюються ланцюжки, то чому ця відстань вже не є оптимальною при збільшенні покриття до 0,3? 3 іншого боку, якщо на відстані 5,0 А адатоми притягуються один до одного, то чому при малих покриттях не спостерігається формування великих острівців структури $(\sqrt{ } 3 \times \sqrt{ } 3) \mathrm{R} 30^{\circ}$ ? Для відповіді на ці питання ми провели моделювання процесу формування структур методом Монте-Карло в моделі граткового газу, використання якої у даному випадку є цілком виправданим тією обставиною, що адатоми хлору на поверхні $\operatorname{Ag}(111)$ займають практично еквівалентні $f c c$ та $h c p$ адсорбційні центри потрійної симетрії (різниця енер- 
гій зв'язку для хлору в $f c c$ та $h c p$ центрах становить менш $0,01 \mathrm{eB}[10,15])$.

\section{2. Методика}

Розрахунки енергії латеральної взаємодії проводились у межах теорії функціоналу електронної густини за допомогою програмного пакета ABINIT [18] 3 використанням норм-зберігаючих псевдопотенціалів [19] та обмінно-кореляційного потенціалу в наближенні узагальненого градієнта густини [20]. Розрахунки для поверхні проводились в моделі повторюваних шарів з атомами хлору, адсорбованими на одному боці шару. Елементарна комірка складалася з чотирьох атомних площин $\mathrm{Ag}(111)$, шару адсорбованого хлору і вакуумного зазору товщиною $10 \AA$. Латеральну взаємодію між адсорбованими атомами $\mathrm{Cl}$ на поверхні $\operatorname{Ag}(111)$ розраховували з використанням поверхневої елементарної комірки розміром $(3 \times 3)$.

Положення адсорбованих атомів хлору і двох верхніх шарів поверхні $\mathrm{Ag}(111)$ оптимізувалося доки сили, що діяли на атоми, не ставали меншими $0,03 \mathrm{eB} / \AA$. Ефективність розбиття зони Бріллюена перевіряли з використанням різних граток для $\mathbf{k}$-точок $[18,21]$ потрібного для досягнення збіжності 0,01 еВ для повної енергії і $0,01 \AA$ для положення атомів. Для поверхневої комірки $(3 \times 3)$ потрібна збіжність досягалася при використанні набору $33 \times 3 \times 1$ спеціальних точок [21]. Всі розрахунки проведено з енергією відсічки 30 Hartree. Більш детальне описання застосованих методів розрахунку енергій зв'язку і латеральної взаємодії наведено в роботах $[15,16,22]$.

Моделювання процесу формування структур хлору на поверхні $\mathrm{Ag}(111)$ методом Монте-Карло проводили за допомогою оригінальних програм, апробованих при моделюванні процесу формування упорядкованих структур для різних адсорбційних систем $[15,16,22-26]$. У цьому методі використано стандартний алгоритм Метрополіса в моделі граткового газу з урахуванням далекодійної латеральної взаємодії між частинками, адсорбованими на поверхні $\operatorname{Ag}(111)$, представленої граткою $60 \times 36$ адсорбційних центрів (що відповідає ділянці поверхні приблизно $100 \times 100$ $\AA^{2}$ ) $з$ періодичними граничними умовами. Упорядкування частинок проведено шляхом переміщення випадково вибраного адатома у сусідній адсорбційний центр з урахуванням існуючого дифузійного бар'єра. Ймовірність переміщення при заданій температуpi $T$ визначається виразом $\exp (-\Delta E / k T)$, де $\Delta E-$ різниця енергій латеральної взаємодії з іншими адсорбованими атомами для початкової і кінцевої кон- фігурацій. Якщо переміщення в сусідній центр приводить до виграшу в енергії системи $(\Delta E<0)$ або якщо ймовірність переміщення перевищує згенероване випадкове число, то це переміщення реалізується. У протилежному випадку система залишається в початковій конфігурації. У результаті великої кількості $\left(10^{5}\right)$ статистичних випробувань встановлюється термодинамічно рівноважна конфігурація адсорбованого шару. При температурах, нижчих температури переходу порядок-непорядок, шар має структуру, для якої енергія латеральної взаємодії мінімальна, а за більш високих температур важливу роль відіграють флуктуації (енергетично невигідні переміщення), що приводять до розупорядкування шару.

\section{3. Результати}

Для моделювання необхідно визначити енергії латеральної взаємодії для різних міжатомних відстаней. Відстані між адатомами $\mathrm{Cl}$, розташованими в $f c c$ та $h c p$ центрах на поверхні $\mathrm{Ag}(111)$, становлять для перших п'яти сусідів 1,$67 ; 2,89 ; 3,34 ; 4,41 ; 5,01$ і $5,78 \AA$, відповідно. Безпосередній розрахунок з перших принципів, фактично, обмежується розміром поверхневої елементарної комірки, при якому такий розрахунок $є$ практично здійсненим, а також обмеженою точністю обчислень (порядку декількох меВ), тоді як формування розріджених структур потребує урахування латеральної взаємодії на значно більших відстанях, причому виявляється дуже чутливим до порівняно малих змін енергетичних параметрів.

Формування ланцюжків свідчить про те, що поряд 3 диполь-дипольним відштовхуванням $2 \mu^{2} / r^{3}$, де $r-$ відстань між адатомами, $\mu$ - дипольний момент, між адатомами хлору існує притягання, зумовлене, очевидно, непрямою взаємодією через електронну систему поверхні: $V(r) \sim \cos \left(2 k_{\mathrm{F}} r+\delta\right) / r^{n}[27-29]$. Період фриделівських осциляцій [30] визначається фермієвським вектором $k_{\mathrm{F}}$, а фазовий зсув $\delta$ визначає положення першого мінімуму потенціалу. Асимптотика непрямої взаємодії залежить від розмірності системи і форми поверхні Фермі. Так, для вільних електронів в об'ємі Лау і Коном [28] було передбачено наявність такої осцилюючої взаємодії, залежної від відстані як $1 / r^{5}$, так що взаємодія між адсорбованими частинками, зумовлена об'ємними електронними станами, затухає значно швидше, ніж диполь-дипольна та пружна взаємодія, і тому не може пояснити формування довгоперіодних структур. Слід відзначити, однак, що 


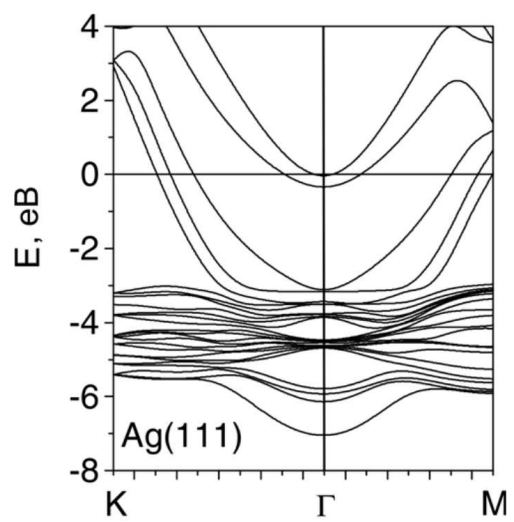

Рис. 2. Зонна структура $\operatorname{Ag}(111)$. Усереднений за напрямками фермї̈вський хвильовий вектор $k_{\mathrm{F}} \sim 0,5 \AA^{-1}$

асимптотика затухання $1 / r^{5}$ справедлива тільки для ізотропних поверхонь Фермі.

Як показали Лау і Кон [28], екранування у двовимірному електронному газі має далекодійний характер з асимптотикою затухання $1 / r^{2}$. Такий $2 \mathrm{D}$ газ майже вільних електронів реалізується у поверхневих станах щільноупакованих поверхонь благородних металів. Ці стани локалізовані поблизу центра першої зони Бріллюена, так що їм відповідають дуже малі хвильові вектори, тому фриделівські осциляції, зумовлені поверхневими станами, мають значно більшу довжину хвилі, ніж об'ємні стани [31-37]. Зокрема, для поверхні $\mathrm{Ag}(111)$ розрахована зонна структуpa дає поверхневий стан $3 k_{\mathrm{F} \text {,surf }}=0,083 \AA^{-1}$ [31]. Це значення ферміївського вектора відповідає періоду фриделівських осциляцій $38 \AA$, який узгоджується 3 довжиною поверхневих хвиль зарядової густини, що спостерігаються на цій поверхні [33], а також 3 положеннями першого мінімуму для потенціалу латеральної взаємодії на поверхні $\mathrm{Ag}(111)$ (27 А для Со i $32 \AA$ для Ce [33, 34]).

Очевидно, настільки великий період осциляцій потенціалу, зумовлений малим ферміївським вектором для поверхневих електронних зон, не дозволяє використовувати його для пояснення формування структур адсорбованих шарів із значно меншими міжатомними відстанями. 3 іншого боку, усереднений за напрямками ферміївський хвильовий вектор для електронів в об'ємі $\mathrm{Ag}$ дорівнює $1,2 \AA^{-1}$ [37], що також виглядає мало придатним для оцінювання взаємодії на поверхні. Крім того, асимптотика взаємодії $1 / r^{5}$, що властива фриделівським осциляціям для сферичної поверхні Фермі, свідчить про його неефективність на відстанях у декілька сталих гратки.

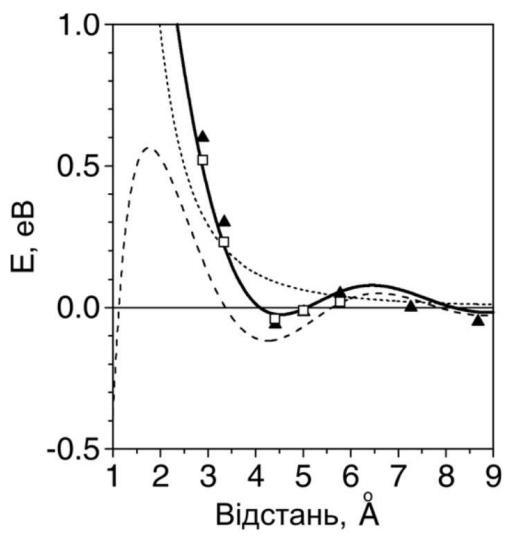

Рис. 3. Ефективний потенціал латеральної взаємодії (суцільна лінія), розраховані енергії взаємодії (квадрати) та параметри, що використовувались при моделюванні методом Монте-Карло (трикутники). Складові потенціалу - диполь-дипольна та непряма взаємодії - показані штриховими лініями

Розв'язок проблеми було знайдено у недавніх роботах Сілкіна та ін. [38], які провели ретельний розрахунок осциляцій густини заряду, індукованих зовнішнім збудженням (адсорбцією) на поверхні $\mathrm{Cu}(111)$, у межах теорії лінійного відгуку. У розрахунках враховувалося співіснування 3D та 2D електронних систем (об'єму і $s-p_{z}$ поверхневих зон, що формують двовимірну електронну систему). Найважливішим результатом роботи є переконливий доказ суттєвого впливу такого співіснування 3D та 2D електронних систем на індуковані осциляції електронної густини в поверхневій області, що приводить у випадку статичного збудження, до асимптотики $1 / r^{2}$ в обох електронних системах. Таким чином, поверхнева і об'ємна електронні системи не є незалежними, тому нехтування роллю електронів об'єму в екрануванні зарядженого атома на поверхні є вельми грубим наближенням. Звідси випливає також, що найбільш придатним для оцінки періоду осциляцій може бути значення $k_{\mathrm{F}}$, що відповідає області, де проекція об'ємних зон (або окремі зони, що отримуються під час розрахунків у моделі повторюваних шарів) перетинає рівень Фермі (рис. $2)$. Оцінка для поверхні $\mathrm{Ag}(111)$ дає $k_{\mathrm{F}}$ у діапазоні від 0,5 до $0,8 \AA^{-1}$, що відповідає періоду осциляцій потенціалу від $6,28 \AA$ до $3,93 \AA$. Саме такого порядку виявляються міжатомні відстані у структурах хлору, які формуються на поверхні $\mathrm{Ag}(111)$ [9], що свідчить на користь запропонованого пояснення їх формування як результату непрямої взаємодії за участю електронів об'єму, яке має таку ж саму асимптотику, як і взаємодія, зумовлена фриделівськими осциляціями у двовимірному газі, тобто $1 / r^{2}$. Відзначимо також, 

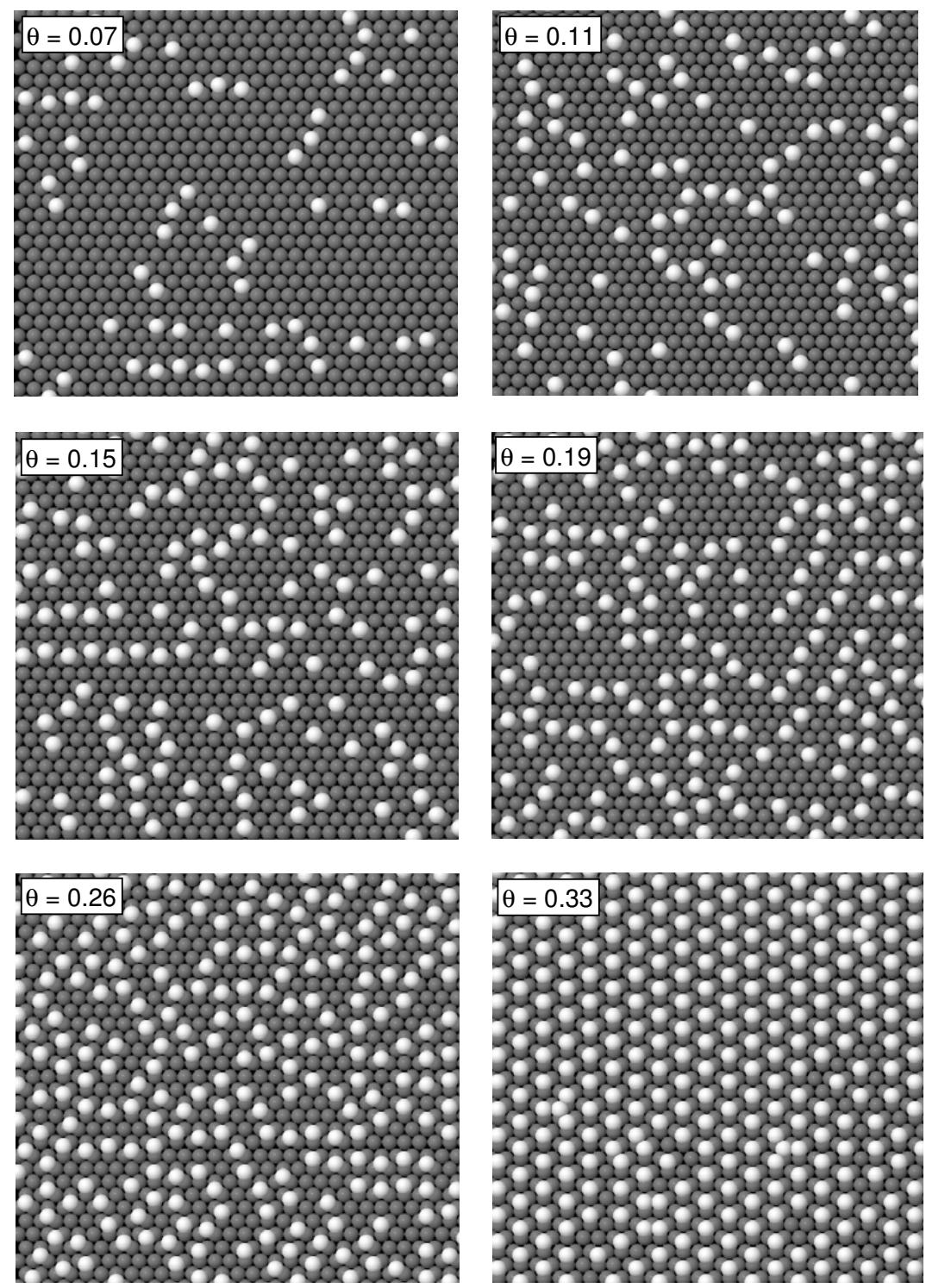

Рис. 4. Структури, отримані при моделюванні методом Монте-Карло. При малих покриттях формуються фрагменти ланцюжків адатомів $\mathrm{Cl}$, а зі збільшенням покриття формується структура $(\sqrt{ } 3 \times \sqrt{ } 3) \mathrm{R} 30^{\circ}$

що правильність вибору такої форми ефективного потенціалу і асимптотики $1 / r^{2}$ для непрямої взаємодії було підтверджено як експериментально [33], так і за допомогою моделювання процесу формування структур CO на $\operatorname{Pt}(111)$ методом Монте-Карло [24].

Ми прийняли, що ефективний потенціал латеральної взаємодії $V(r)$ для адатомів хлору на поверхні $\operatorname{Ag}(111)$ може бути поданий як сума енергій дипольдипольної і непрямої взаємодії:

$V(r)=\frac{2 \mu^{2}}{1,6 r^{3}}+\frac{A}{r^{2}} \cos \left(2 k_{\mathrm{F}} r+\delta\right)$.
Амплітуда $A$ i дипольний момент $\mu$ (множник 1,6 у знаменнику дозволяє отримати значення потенціальної енергії в еВ при $\mu$ в Дебаях) вибиралися так, щоб результуючий ефективний потенціал якнайкраще відповідав значенням енергій латеральної взаємодії, обчисленим із перших принципів (рис. 3).

Результати моделювання - структури, що формуються адатомами хлору при різних ступенях покриття і достатньо низьких температурах - наведено на рис. 4. У повній відповідності до експерименту [9] при малих покриттях утворюються фрагменти ланцюжків 3 міжатомною відстанню 4,41 ̊, а при наближенні до 
ступеня покриття 0,33 на поверхні $\mathrm{Ag}(111)$ формується сумірна ґратка хлору $(\sqrt{ } 3 \times \sqrt{ } 3) \mathrm{R} 30^{\circ}$, міжатомні відстані в якій дорівнюють $5,01 \AA$.

Цікаво проаналізувати механізм перетворення ланцюжкових структур у структуру $(\sqrt{ } 3 \times \sqrt{ } 3) R 30^{\circ}$. Для обох цих структур (для ланцюжкової - вздовж ланцюжка, а для $(\sqrt{ } 3 \times \sqrt{ } 3) \mathrm{R}^{\circ} 0^{\circ}$ - вздовж шести еквівалентних напрямків) характерною є міжатомна відстань 8,67 ̊ (рис. 1,a, б). Такій відстані між адатомами відповідає латеральне протягування (рис. 3), яке і приводить до формування цих структур. При малих покриттях найбільш вигідною відстанню між адатомами хлору, що знаходяться в адсорбційних центрах потрійної симетрії на поверхні $\mathrm{Ag}(111)$, є відстань 4,41 $\AA$ (див. рис. 1), тому формуються зигзагоподібні ланцюжки, в яких атоми послідовно займають $f c c$ та $h c p$ центри. Зі збільшенням ступеня покриття відстань між такими ланцюжками зменшується, і настає момент, коли переміщення кожного другого атома у ланцюжку в сусідній адсорбційний центр приводить до формування структури $(\sqrt{ } 3 \times \sqrt{ } 3) \mathrm{R}^{\circ}$ з відстанню між атомами 5,01 А. Такій відстані між адатомами також відповідає притягання (див. рис. 3), хоча і менше, ніж на відстані $4,41 \AA$. Однак у структурі $(\sqrt{ } 3 \times \sqrt{ } 3) \mathrm{R} 30^{\circ}$ кожний атом має шість сусідів, що розташовані на однаковій (вигідній) відстані 5,01 ланцюжку має тільки двох відповідних сусідів. Таким чином, послаблення притягальної взаємодії між атомами у структурі $(\sqrt{ } 3 \times \sqrt{ } 3) \mathrm{R} 30^{\circ}$ компенсується збільшенням кількості атомів, що взаємодіють на відстані 5,01 $\AA$, і тому структура $(\sqrt{ } 3 \times \sqrt{ } 3) \mathrm{R} 30^{\circ}$ $\epsilon$ більш енергетично вигідною при ступені покриття 0,33 .

\section{4. Висновки}

Моделювання методом Монте-Карло з використанням параметрів латеральної взаємодії, розрахованих методом теорії функціонала електронної густини, показало, що формування ланцюжків зумовлене непрямою взаємодією між адатомами хлору. Результати моделювання дозволили пояснити послідовність формування структур хлору на поверхні $\mathrm{Ag}(111)$, що спостерігається в експерименті методом СТМ. Зокрема показано, що взаємодія між адсорбованими атомами добре описується моделлю, що враховує диполь-дипольну взаємодію та взаємодію, зумовлену фриделівськими осциляціями електронної густини. За допомогою моделювання вдалось пояснити експериментально спостережуване перетворення ланцюжкової структури в гексагональну, що супроводжується збільшенням відстані між найближчими атомами хлору у разі збільшення концентрації адатомів.

Дану роботу виконано в рамках Українськоросійського гранту НАНУ /РФФД № РФФД/3-11-26.

1. G. Rovida and F. Pratesi, Surf. Sci. 51, 270 (1975).

2. P.J. Goddard and R.M. Lambert, Surf. Sci. 67, 180 (1977).

3. M. Bowker and K.C. Waugh, Surf. Sci. 134, 639 (1983); K. Wu, D. Wang, J. Deng, X. Wei, Y. Cao, M. Zei, R. Zhai, and Z. Gao, Surf. Sci. 264, 249 (1992).

4. B.V. Andryushechkin, K.N. Eltsov, V.M. Shevlyuga, and V.Yu. Yurov, Surf. Sci. 407, L633 (1998); 431, 96 (1999).

5. A.G. Shard and V.R. Dhanak, J. Phys. Chem. B 104, 2743 (2000).

6. G.M. Lamble, R.S. Brooks, S. Ferrer, D.A. King, and D. Norman, Phys. Rev. B 34, 2975 (1986).

7. J.H. Schott and H.S. White, J. Phys. Chem. 98, 291 (1994).

8. B.V. Andryushechkin, V.V. Cherkez, E.V. Gladchenko, G.M. Zhidomirov, B. Kierren, Y. Fagot-Revurat, D. Malterre, and K.N. Eltsov, Phys. Rev. B 81, 205434 (2010).

9. Б.В. Андрюшечкин, Е.В. Гладченко, К. Дидье, К.Н. Ельцов, Г.М. Жидомиров, Б. Керрен, В.В. Черкез, Труды ИОФ РАН 66, 20 (2010).

10. K. Doll and N.M. Harrison, Phys. Rev. B 63, 165410 (2001).

11. Y. Wang, Q. Sun, K. Fan, and J. Deng, Chem. Phys. Lett. 334, 411 (2001).

12. N.H. de Leeuw, C.J. Nelson, C.R.A. Catlow, P. Sautet, and W. Dong, Phys. Rev. B 69, 045419 (2004).

13. A. Migani and F. Illas, J. Phys. Chem. B 110, 11894 (2006).

14. P. Gava, A. Kokalj, S. Gironcoli, and S. Baroni, Phys. Rev. B 78, 165419 (2008).

15. N.V. Petrova, I.N. Yakovkin, and O.M. Braun, Chem. Phys. 383, 35 (2011).

16. Н.В. Петрова, І.М. Яковкін, О.М. Браун, УФЖ Т. 56, N4, 367 (2011).

17. H. Piao, K. Adib, and M.A. Barteau, Surf. Sci. 557, 13 (2004).

18. X. Gonze, J.-M. Beuken, R. Caracas, F. Detraux, M. Fuchs, G.-M. Rignanese, L. Sindic, M. Verstraete, G. Zerah, F. Jollet, M. Torrent, A. Roy, M. Mikami, Ph. Ghosez, J.-Y. Raty, and D.C. Allan, Comput. Mat. Sci. 25, 478 (2002). 
19. N. Troullier and J. L. Martins, Phys. Rev. B 43, 1993 (1991)

20. J.P. Perdew, K. Burke, and M. Ernzerhof, Phys. Rev. Lett. 77, 3865 (1996).

21. H.J. Monkhorst and J.D. Pack, Phys. Rev. B 13, 5188 (1976).

22. N.V. Petrova and I.N. Yakovkin, Phys. Rev. B 76, 205401 (2007).

23. N.V. Petrova, I.N. Yakovkin, and Yu.G. Ptushinskii, Eur. Phys. J. B 38, 525 (2004).

24. N.V. Petrova and I.N. Yakovkin, Surf. Sci. 578, 162 (2005).

25. Н.В.Петрова, И.Н.Яковкин, Ю.Г.Птушинский, ФНТ T. 31, N 34, c. 300 (2005).

26. С.М. Орлик, С.О. Соловйов, Н.В. Петрова, І.М. Яковкін, УФЖ 4, 64 (2008).

27. T.L. Einstein, CRC Crit. Rev. Solid State Mater. Sci. 7, 261 (1978); Surf. Sci. 75, L161 (1978).

28. K.H. Lau and W. Kohn, Surf. Sci. 65, 607 (1977); 75, 69 (1978)

29. O.M. Braun and V.K. Medvedev, Sov. Phys. Usp. 32, 328 (1989).

30. J. Friedel, Nuovo Cimento Suppl. 7, 287 (1958).

31. O. Jeandupeux, L.Bürgi, A. Hirstein, H. Brune, and K. Kern, Phys. Rev. B 59, 15926 (1999).

32. P. Hyldgaard and M. Persson, J. Phys.: Condens. Matter 12, L13 (2000).

33. N. Knorr, H. Brune, M. Epple, A. Hirstein, M.A. Schneider, and K. Kern, Phys. Rev. B 65, 115420 (2002).

34. N.N. Negulyaev, V.S. Stepanyuk, W. Hergert, H. Fangohr, and P. Bruno, Surf. Sci. 600, L58 (2006).

35. M. Kulawik, H.-P. Rust, M. Heyde, N. Nilius, B.A. Mantooth, P.S. Weiss, and H.-J. Freund, Surf. Sci. 590, L253 (2005).

36. J. Repp, F. Moresco, G. Meyer, K.-H. Rieder, P. Hyldgaard, and M. Persson, Phys. Rev. Lett. 85, 2981 (2000).

37. Ч. Киттель, Введение в физику твердого тела (Наука, Москва, 1978), 790 с.
38. V.M. Silkin, I.A. Nechaev, E.V. Chulkov, and P.M. Echenique, Surf. Sci. 588, L239 (2005).

Одержано 05.07.2011

\section{АТОМНЫЕ ЦЕПОЧКИ ХЛОРА НА ПОВЕРХНОСТИ}

$\operatorname{Ag}(111)$

Н.В. Петрова, И.Н. Яковкин, О.М. Браун

$\mathrm{P}$ е $з$ ю м е

Формирование цепочечных структур хлора на поверхности $\operatorname{Ag}(111)$ исследовано методом Монте-Карло с использованием параметров латерального взаимодействия, рассчитанных методом теории функционала электронной плотности. Показано, что формирование цепочек обусловлено непрямым взаимодействием между адатомами хлора, являющимся следствием фриделевских осцилляций электронов проводимости подложки при экранировании частично заряженных адатомов. Проведенное моделирование позволяет объяснить наблюдаемую в эксперименте последовательность формирования структур хлора на поверхности $\mathrm{Ag}(111)$, в частности, переход от цепочечной структуры к гексагональной структуре $(\sqrt{ } 3 \times \sqrt{ } 3) \mathrm{R} 30^{\circ}$ при увеличении степени покрытия до $\theta=0,33$.

\section{CHLORINE ATOMIC CHAINS ON Ag(111) SURFACE}

N.V. Petrova, I.N. Yakovkin, O.M. Braun

Institute of Physics, Nat. Acad. of Sci. of Ukraine

(46, Prosp. Nauky, Kyiv 03028, Ukraine;

e-mail: yakov@iop.kiev.ua)

$\mathrm{S}$ u m m a r y

The formation of chlorine chain structures on an $\mathrm{Ag}(111)$ surface is studied within the Monte-Carlo simulation method. Parameters of the lateral interaction calculated in the framework of density functional theory are used. The chain formation was shown to stem from the indirect interaction between chlorine adatoms owing to Friedel oscillations of the conduction electron concentration emerging when partially charged adatoms are screened. The numerical simulation allowed the formation of the experimentally observed sequence of chlorine structures on the $\operatorname{Ag}(111)$ surface to be explained. In particular, the mechanism of transformation from the chain structure into the hexagonal $(\sqrt{ } 3 \times \sqrt{ } 3) \mathrm{R} 30^{\circ}$ one as the coverage increases to $\theta=0.33$ has been elucidated. 